\title{
Sepultamentos secundários com manipulações intencionais no Brasil: um estudo de caso no sítio arqueológico Pedra do Cachorro, Buíque, Pernambuco, Brasil \\ Secondary burials with intentional manipulation in Brazil: a case study on the archaeological site Pedra do Cachorro, Buíque, Pernambuco, Brazil
}

\author{
Ana Solaril, Sérgio Francisco Serafim Monteiro da Silva ${ }^{\mathrm{I}}$ \\ Universidade Federal de Pernambuco. Recife, Pernambuco, Brasil
}

Resumo: Este artigo apresenta o estudo de caso de um sepultamento secundário escavado no sítio Pedra do Cachorro, $760 \pm$ 30 A.P., Buíque, em Pernambuco, Brasil, contendo remanescentes ósseos humanos de um indivíduo adulto, masculino, cuja análise bioarqueológica revelou sinais de descarnamento ativo do cadáver e outras evidências de manipulação intencional em ossos frescos, como cortes, fraturas, golpes e esmagamento. A metodologia de análise adotada para a identificação das manipulações perimortem nos ossos permite a reflexão acerca da complexidade desta prática funerária e do seu contexto em relação a outros achados arqueológicos da pré-história brasileira.

Palavras-chave: Sepultamentos secundários. Manipulações intencionais. Bioarqueologia. Nordeste brasileiro. Pedra do Cachorro.

\begin{abstract}
This article reports on a case study of a secondary burial excavated at the site Pedra do Cachorro, $760 \pm 30$ B.P., Buíque, Pernambuco, Brazil. This site contains human bone remains of an adult male individual, whose bioarchaeological analysis revealed signs of active defleshing of the body and other evidence of intentional manipulation of fresh bones, such as cuts, fractures, blows and crushing. The methodology of analysis used to identify perimortem manipulation of bones, may help to understand the complexity of this funerary practice and its context in relation to other archaeological finds from Brazilian prehistory.
\end{abstract}

Keywords: Secondary burials. Intentional manipulation. Bioarcheology. Brazilian Northeast. Pedra do Cachorro.

SOLARI, Ana; MONTEIRO DA SILVA, Sérgio Francisco Serafim. Sepultamentos secundários com manipulações intencionais no Brasil: um estudo de caso no sítio arqueológico Pedra do Cachorro, Buíque, Pernambuco, Brasil. Boletim do Museu Paraense Emílio Goeldi. Ciências Humanas, v. 12, n. 1, p. 135-155, jan.-abr. 2017. DOI: http://dx.doi.org/10.1590/1981.81222017000100008.

Autora para correspondência: Ana Solari. Universidade Federal de Pernambuco. Departamento de Arqueologia. Av. Prof. Moraes Rego, 1235 - Cidade Universitária. Recife, PE, Brasil. CEP 50670-901 (anasolari74@gmail.com).

Recebido em 02/06/2016

Aprovado em 20/07/2016

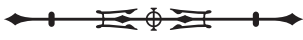




\section{INTRODUÇÃO}

A recente descoberta e escavação de uma deposição funerária em cova do tipo secundário simples, com evidências de manipulação intencional em um sítio arqueológico do Nordeste brasileiro, possibilitaram a reflexão sobre a existência e extensão desse tipo de prática nos contextos arqueológicos pré-históricos brasileiros, possibilitando também a reflexão sobre os modos de tratamento e disposição do corpo, que caracterizam esta forma de tratamento mortuário.

Nesse sentido, este trabalho pretende discutir uma prática funerária específica, os sepultamentos secundários, e, em particular, busca aprofundar-se na metodologia de análise de casos envolvendo o descarnamento ativo do cadáver e outras formas de manipulação intencional do corpo. Para isso, foram revisadas algumas definições que auxiliam no reconhecimento desse tipo de prática funerária no contexto arqueológico e suas evidências em alguns sítios do Brasil. Em seguida, focando na metodologia de identificação de manipulações perimortem nos ossos, apresentamos um caso particular do Nordeste brasileiro, escavado no sítio Pedra do Cachorro, município de Buíque, estado de Pernambuco.

\section{CONSIDERAÇÕES TEÓRICAS SOBRE OS ENTERRAMENTOS SECUNDÁRIOS}

A partir das aproximações da Antropologia, Etnologia, História e Arqueologia, sabe-se que existem distintos modos mediante os quais as sociedades humanas do passado se ocuparam de seus mortos. Isso inclui uma ampla variedade de práticas funerárias, com numerosos modos de tratamento e deposição dos cadáveres, determinada por múltiplas dimensões, como as ambientais, sociais, culturais, econômicas, religiosas e ideológicas (Ucko, 1969; Hertz, 1960; Metcalf, 1981; Saxe, 1970; Carr, 1995; Tainter, 1978; Brown, 1981).

Nesse contexto, estão inseridas as práticas mortuárias envolvendo procedimentos que podem deixar sinais detectáveis nos ossos, com o objetivo de acelerar o processo de decomposição do corpo, como o descarnamento ativo. Tais práticas resultam em deposições ósseas desarticuladas e fragmentadas, incluindo indicadores da presença de pelo menos uma deposição inicial e outra final, classificados como sepultamentos do tipo secundários ou compostos, que são o foco do presente trabalho.

Apesar de certa falta de consenso terminológico, são muitos os autores que estudam a classificação das formas de deposição funerária, em particular sobre os sepultamentos primários e secundários (Duday, 2009a, 2009b; Duday et al., 1990; Huntington; Metcalf, 1979; Metcalf, 1981; Miles, 1965; Parker Pearson, 1999; Schroeder, 2001; Sprague, 1968, 2005; Ubelaker, 1989; Ucko, 1969). Especificamente, neste estudo, optou-se pelas definições empregadas por Ubelaker (1989), Duday et al. (1990), Duday (2009a, 2009b), Schroeder (2001) e Sprague (2005), que se complementam para permitir adequados reconhecimento e interpretação dos sepultamentos do tipo secundário em um contexto arqueológico.

A respeito deste assunto, Ubelaker (1989) define os enterros secundários como coleções ou agrupamentos de ossos não articulados no contexto de uma escavação arqueológica, que seriam o resultado de um complicado tratamento do cadáver, envolvendo dois ou mais estágios, incluindo a remoção da carne, com uso de ferramentas ou por decomposição natural; o agrupamento ou desenterro dos ossos depois de um período de tempo; e o enterro definitivo, de forma individual ou coletiva.

Por sua parte, para Duday et al. (1990), os sepultamentos secundários, também conhecidos como sepultamentos em dois ou mais tempos, são aqueles onde o depósito de remanescentes humanos é precedido por uma fase de descarnamento (ativo ou passivo), que se desenvolve necessariamente em outro lugar. Entre os principais argumentos defendidos por esses autores para demonstrar a existência de sepultamentos secundários, estariam: 1) a presença de marcas de corte como testemunho de um descarnamento ativo do cadáver, 
compreendendo a remoção dos tecidos moles com ferramentas cortantes; 2) a ausência de ossos e o caráter incompleto dos esqueletos, por uma separação voluntária de alguns ossos selecionados para seu enterramento definitivo ou pelo esquecimento, perda ou destruição de pequenos ossos no local de descarnamento ou durante o transporte de um lugar para outro, conquanto essa ausência não seja decorrente de causas tafonômicas naturais de destruição do tecido ósseo; e 3) uma 'desordem' aparente na disposição dos remanescentes humanos, em oposição a um esqueleto articulado, ainda que algumas conexões anatômicas persistentes possam ser observadas.

Entretanto, quando considerada isoladamente, a desarticulação anatômica do esqueleto por si só não é conclusiva para demonstrar o caráter secundário de um sepultamento, pois se sabe que, em sepultamentos primários, algumas articulações podem ser perdidas por fatores formativos do depósito, enquanto, nos sepultamentos secundários, podem persistir conexões mesmo após os processos redutivos intencionais do corpo. Ainda, o critério relacionado à presença de marcas nos ossos, associadas ao descarnamento ou maceração, pode não ser efetivo para identificar enterros secundários, pois elas podem estar associadas a outros comportamentos mortuários diferentes, como trepanações, lesões por traumas e canibalismo, que nem sempre estão associadas ao ciclo funerário. Por esses motivos, a identificação de enterramentos secundários é geralmente feita com dificuldade, devido ao caráter heterogêneo do comportamento funerário relacionado com esses tipos de enterros (Duday, 2009a).

Também, de acordo com Duday (2009b), os sepultamentos secundários são definidos com critérios opostos aos usados para caracterizar os sepultamentos primários, dados pela conexão anatômica das articulações lábeis e persistentes - mesmo considerando as mudanças causadas pelo processo de decomposição do cadáver, como o achatamento da caixa torácica, o deslocamento parcial da coluna vertebral e o colapso da cintura pélvica -, e as suas intensidades, conforme os espaços internos e do exterior do corpo, no recipiente ou na cova. A complexidade de identificação dos sepultamentos secundários aumenta nas deposições múltiplas e nos enterramentos coletivos com processos naturais e culturais formadores do depósito arqueológico já instalados.

Ao mesmo tempo, de acordo com Schroeder (2001), a disposição secundária dos mortos é um tipo específico de ritual funerário, onde se produz um novo enterramento intencional dos remanescentes humanos. Nos enterramentos secundários, o corpo é depositado inicialmente, de alguma maneira, após a morte, para depois, em uma segunda sequência de tratamento mortuário e após um determinado lapso de tempo culturalmente determinado, os restos serem removidos de seu lugar de deposição inicial, para, finalmente, serem dispostos no mesmo ou em outro lugar distinto.

Por último, em relação à forma de deposição dos mortos, as deposições compostas, segundo Sprague (2005), envolvem ao menos dois processos: de redução do corpo e o depósito secundário ou final dos seus remanescentes. O processo de redução pode incluir, para esse autor, o enterro e subsequente exumação, descarnamento por exposição ao ar livre, fermentação por armazenamento em contenedores, exposição do cadáver a animais, descarnamento mecânico, cremação e decomposição química. Posteriormente ao processo redutivo, é dada sequência a uma deposição secundária ou final.

De acordo com a literatura sobre o tema vemos que, em definitivo, é o antropólogo biólogo ou arqueólogo quem, no presente, deve reconhecer os traços de intencionalidade na deposição final observada e, ao mesmo tempo, deve perceber os sinais das etapas precedentes da deposição transitória, incluindo a redução do corpo nos casos de um descarnamento ativo. A partir dessas considerações, torna-se possível diferenciar os sepultamentos secundários dos contextos primários perturbados ou de outros tipos de depósitos não secundários, que sejam produto da ação de diversos fatores tafonômicos culturais e/ou naturais. 


\section{OS SEPULTAMENTOS SECUNDÁRIOS NO BRASIL}

No Brasil, a forma de classificar as deposições funerárias varia conforme a orientação teórica e metodológica dos arqueólogos. Autores fazem referência a conceitos em arqueologia funerária e descrições etnográficas de sepultamentos secundários, procurando compreender os contextos arqueológicos escavados conforme os parâmetros escolhidos. Torna-se evidente a carência de uma metodologia e de técnicas de campo que sejam satisfatórias para a interpretação das deposições compostas ou secundárias nos sítios arqueológicos brasileiros, como também o fato de haver uma heterogeneidade dissonante de terminologias e conceitos, relativos às instâncias operacionais das práticas mortuárias e sua observação nos diversos contextos arqueológicos, dificultando a reunião e o estudo cientíico comparativo, integrado e amplo dos dados mortuários.

Entretanto, alguns dos parâmetros para a distinção das deposições funerárias, secundárias ou compostas, no contexto arqueológico incluem: desarticulação do esqueleto, ausência de pequenos ossos, desarranjo no recipiente ou cova e sinais de manipulação perimortem ou postmortem, como redução do corpo (cortes, decomposição acelerada, exposição ao fogo) e tratamento dos ossos pela pigmentação ou outros meios. Igualmente, fatores tafonômicos naturais ou culturais podem mascarar sepultamentos primários que, durante a escavação arqueológica, são erroneamente classificados, algumas vezes, como secundários por causa da presença de ossos desarticulados ou dificuldade de reconhecimento in situ. Por isso, a presença de instâncias operacionais com sinais de intencionalidade antrópica é fundamental nessa distinção dos tipos secundários de inumação.

No âmbito dos estudos antropológicos, são descritas as formas de deposição funerária composta ou sepultamentos secundários enquanto estruturas que implicam a presença de uma etapa de preparação do corpo, resultando na sua redução por descarnamento, desmembramento, queima ou rearticulação dos ossos em uma cova permanente
(Silva, 2005). Esse tipo de sepultamento, descrito por Baldus e Willems (1939), Cruz (1944), Hensel, R. e Hensef, Reinhold (1869) e Boggiani (1930), é recorrente na bibliografia antropológica. Relatos etnográficos sobre as formas de deposição composta dos cadáveres entre os povos indígenas do Brasil - e América do Sul - estão presentes em Hensel, R. e Hensef, Reinhold (1869), Kroeber (1927), Boggiani (1930), Métraux (1947), Ramos (1951), Baldus (1954), Lowie (1963), Carneiro da Cunha (1978), Lévi-Strauss (1993) e Gaspar (1994-1995), por exemplo, incluindo-se, neste conjunto, o texto sobre os enterros em urnas dos Guarani, escrito por César (1972).

Segundo este último, "há autores que falam tão só de enterros diretos e indiretos, significando com isso os primários e secundários em urnas" (César, 1972, p. 27). Para César (1972, p. 28), os enterros em urnas poderiam ser primários, quando o corpo é depositado "sem demora" - inteiro e com carnes - no recipiente cerâmico, ou secundários, quando os ossos, uma vez desenterrados, são depositados no recipiente de uso funerário. Este autor considera secundárias as deposições de ossos queimados ou de suas cinzas diretamente em covas no solo ou em vasilhames cerâmicos, e os atribui aos Mundurucu, Curuaia, Oiampi e Aicauá. Os sepultamentos secundários foram atribuídos aos Ature (norte do Amazonas), Rucuyenne (Brasil Central) e aos Carajá e Camacã, da Bahia (César, 1972). Na região da Amazônia, a memória, a alteridade e o tratamento diversificado dado aos mortos, incluindo o uso dos ossos e as suas formas e lugares de deposição, são objeto de estudo de Chaumeil (2007), que também trata brevemente das inumações secundárias.

Segundo Müller e Souza (2011a), que analisaram dois casos de vasilhas Guarani com função funerária e os tipos de deposições nelas realizadas, para esta cultura estão descritas, na bibliografia arqueológica, a presença de enterros primários e de enterros secundários (Prous, 1992; Noelli, 1993). Todavia, o estado de conservação ruim dos ossos nesses vasilhames cerâmicos prejudicou a interpretação sobre a presença de articulação ou não entre eles. Esse aspecto 
também ficou danificado pelas alterações tafonômicas, que resultaram na reacomodação, no esmagamento parcial ou no deslocamento dos ossos. Os sepultamentos, quando não secundários, apresentavam esqueletos com alguns ossos principais semiarticulados ou parcialmente articulados. Ainda, a presença europeia na região do rio Pardo, no Sul do Brasil, teria propiciado o aparecimento dos enterros secundários guaranis em vasilhames cerâmicos, modificando as formas de deposição simples anteriores ao período do contato (Ribeiro, 1978, p. 7-38 apud Müller; Souza, 2011a, p. 213). Nesse sentido, a perspectiva de análise dos remanescentes ósseos humanos quanto à identificação e à interpretação da sua forma de deposição deve seguir a perspectiva metodológica da Bioarqueologia, tanto para os estudos dos sepultamentos secundários, quanto das cremações (Müller; Souza, 2011b).

Ao mesmo tempo, uma revisão preliminar da literatura arqueológica mostra que, apesar da predominância dos sepultamentos primários, ainda têm sido registrados diversos casos de sepultamentos secundários em contextos pré-históricos de caçadorescoletores, horticultores e ceramistas em várias regiões do Brasil. Entre eles, destacam-se alguns apresentando diferentes sinais de manipulação intencional nos corpos. Sem pretender esgotar o assunto, só serão apresentados no presente trabalho, de forma sintetizada, alguns exemplos que permitem refletir sobre a extensão desta prática na pré-história brasileira e que servem de marco geral para o caso discutido seguidamente.

Assim, na região de Lagoa Santa, em Minas Gerais, o sepultamento 3 de Lapa das Boleiras (Neves et al., 2002), datado entre 8.000 e 9.000 anos A.P., estava composto por diversos ossos longos, dispostos paralelamente entre si, formando um feixe, que teriam sido colocados dentro de uma calota craniana. As características e a disposição dos ossos mostraram evidências de procedimentos complexos de secundarização, envolvendo a manipulação do corpo, por meio da remoção intencional dos ossos, assim como: sinais de fraturas intencionais, aplicação de pigmento ocre e ação do fogo.
Na mesma região de Lagoa Santa e com datações entre 8.700 e 690 A.P., destaca-se o sítio de Lapa do Santo, pelos elaborados rituais mortuários usando os corpos dos falecidos como símbolos, de acordo com Strauss (2010, 2014 , 2016). No que se refere ao registro arqueológico, nos sepultamentos do padrão 2 (8.700 a 8.200 A.P.), essas práticas expressaram-se na forma de múltiplas evidências de manipulação intencional perimortem dos corpos, com ossos desarticulados, compostos por: crânios individualizados; fardos de ossos com múltiplos indivíduos; marcas de corte; chanfros; extração de dentes; seleção de partes anatômicas; separação de diáfises e epífises de ossos longos; exposição ao fogo; e aplicação de pigmento ocre-avermelhado (Strauss, 2016). No padrão 3 (7.500 a 6.000 A.P.), os sepultamentos caracterizaram-se por ser enterramentos individuais em covas rasas cobertas por blocos, contendo ossos desarticulados, desordenados, evidenciando ossos longos com fraturas intencionais no tecido ósseo ainda fresco (Strauss, 2016).

Também em Minas Gerais, no abrigo Santana do Riacho, com ocupações humanas datadas entre 11.900 e 2.500 A.P. (Prous, 1992-1993 apud Strauss, 2014), foram observados ossos fora da conexão anatômica ou partes ausentes, que poderiam ter sido resultado de manipulações intencionais do corpo durante o processo funerário, devido a algumas condutas rituais que envolviam algum grau de redução do corpo (Junqueira, 1984 apud Strauss, 2014). Em particular, na ocupação de Santana do Riacho 1, possivelmente existem sinais de manipulação e de redução de corpos, indicadas pela presença de sepultamentos de pés isolados - possivelmente amputados - e um sepultamento contendo partes seccionadas de um esqueleto. Outros indicadores desse processo redutivo são a queima, a aplicação de pigmento ocre e a ausência de ossos em alguns sepultamentos. Por outra parte, um entre os oito sepultamentos evidenciados na ocupação de Santana do Riacho 3 era secundário, com ossos longos dispostos intencionalmente uns sobre os outros. Ainda foram localizadas concentrações de dentes humanos inumados em 
duas deposições, estando uma delas com contas de colar, sob líticos e em matriz de sedimento vermelho.

Na região mineira de Diamantina, o sítio Lapa do Caboclo apresentou sepultamentos em fossas do tipo secundário simples (individuais), com redução ou descarnamento passivo dos cadáveres, datados entre 730 a 1.260 A.P. (Solari et al., 2012). As estruturas funerárias de forma cilíndrica, feitas de cascas de árvores do cerrado e de couro animal, continham os esqueletos de uma criança e de um adulto desarticulados e manipulados intencionalmente com pigmento vermelho (na criança) e cera ou resina avermelhada (no adulto), e apresentavam alguns ossos fraturados peri/postmortem, além do achado de outros depósitos funerários perturbados, que também poderiam ter sido parte de sepultamentos primários e/ou secundários, mas, pelo grau de perturbação, não foi possível sua identificação.

Na região das terras baixas do Amazonas, também podemos fazer menção ao sítio Hatahara, onde, em associação a montículos artificiais pertencentes à fase Paredão (séculos VII a XII), foram registrados, além dos sepultamentos primários, sepultamentos do tipo secundário, individuais e múltiplos, apesar de apresentar grande dificuldade na sua identificação, devido ao seu estado de conservação e perturbação na matriz arqueológica (Rapp Py-Daniel, 2009, 2010), motivo pelo qual não se têm maiores informações sobre os mesmos.

Além destes cenários mortuários, os sambaquis destacam-se, apesar das poucas informações acerca de suas diversificadas práticas funerárias. Enquanto Uchôa (1973) não identificou sepultamentos secundários em Piaçaguera e Tenório, litoral paulista, Gaspar et al. (2008 apud Strauss, 2014) localizaram inúmeros sepultamentos secundários no sambaqui Jabuticabeira II, em Santa Catarina, o que julgaram ser a regra nesse sítio. Nesses casos, os esqueletos estavam desarticulados e incompletos, com pigmentação ocre, com remoção e/ou acréscimo de ossos e com acompanhamentos funerários de artefatos em conchas e líticos.

A presença de sepultamentos secundários, ou de deposições mortuárias compostas, em sítios sambaquis
(1.000 a 10.000 A.P.) tem sido mencionada por autores como Silva (2005), Gaspar et al. (2008), entre outros, muito embora haja poucos casos descritos em detalhes. No sítio conchífero Mar Virado (Silva, 2001, 2005; Uchôa, 2009), situado em São Paulo, na ilha de mesmo nome e datado em cerca de 3.000 A.P., foram escavados quatro sepultamentos com características de deposições compostas. Duas dessas deposições ocorreram em covas circulares, com ossos queimados e misturados de adultos masculino e feminino, classificados como cremações secundárias. Na inumação feminina, observa-se a ausência do crânio, retirado antes da queima dos demais ossos. No terceiro caso, foi escavado um sepultamento secundário duplo com ossos de adulto, dispostos em feixe, e ossos de outro indivíduo, queimados e misturados, todos sob uma carapaça dorsal de quelônio, apoiada por grandes seixos de traquito. No quarto caso, os ossos desarticulados de um subadulto estavam depositados sob ossos de um mamífero marinho.

Na região de Saquarema, no Rio de Janeiro, alguns sítios sambaqui contendo sepultamentos foram estudados por Kneip e Machado (1993). No sambaqui da Pontinha, as autoras identificaram sete deposições compostas ou secundárias (sepultamentos 1, 4, 5, 6, 10, 12 e 16), entre 19 deposições funerárias, as quais estavam representadas por sepultamentos secundários cremados. Já no sambaqui da Beirada, entre 29 deposições funerárias, duas eram do tipo secundário (sepultamentos 6 e 7), onde os ossos apresentavam sedimentos e concreção vermelha.

Entre os sítios arqueológicos com evidências de enterramentos humanos no Nordeste brasileiro, Cisneiros (2004) e Castro (2009) mencionam alguns onde teriam sido identificadas práticas funerárias do tipo secundárias, incluindo ossos desarticulados, fraturados, com sinais de queima e pigmentação ocre-avermelhada, entre eles: Cemitério do Caboclo (Pernambuco), Alcobaça (Pernambuco), Pedra do Alexandre (Rio Grande do Norte), Justino (Sergipe) e São José II (Alagoas).

$\mathrm{Na}$ área arqueológica de Xingó, município de Canindé do São Francisco, no estado da Bahia, divisa com 
Alagoas, o sítio Justino (Vergne, 2002, 2005, 2007) foi caracterizado como uma grande 'necrópole', composta de quatro cemitérios, com vestígios das práticas funerárias associadas a grupos ceramistas (cemitérios A, B e C) e a caçadores-coletores (cemitério $D$, mais profundo e antigo), com datações entre $1.280 \pm 45$ A.P. a $8.950 \pm$ 70 A.P. (Vergne, 2007). A maioria dos enterramentos era primária, com sepultamentos "totalmente articulados" e, em menor quantidade, estavam os "secundários com ossos cuidadosamente arrumados em torno ou partindo de um, até três crânios" (Vergne, 2007, p. 45). Do total de 148 deposições funerárias, Vergne (2002, 2005, 2007) distinguiu 38 deposições compostas (sepultamentos secundários). Entre os grupos ceramistas, foram registrados 106 sepultamentos primários e 37 secundários. Para os caçadores-coletores, Vergne $(2002,2005$, 2007) identificou quatro sepultamentos primários e um secundário.

Também no Nordeste, no abrigo cemitério Pedra do Alexandre, no Rio Grande do Norte, se sucederam as duas formas rituais de enterramentos primários e secundários ao longo do tempo, entre 9.400 e 2.600 anos A.P. Entre eles, destaca-se o sepultamento 1, datado entre 4.000 a 4.700 anos A.P., secundário, contendo ossos sem conexão anatômica de quatro indivíduos (um adulto jovem, duas crianças e um feto a termo), pintados com pigmento vermelho, em uma cova rodeada de lajes de pedra. Também a inumação secundária dupla número 15, que não foi datada, de dois adultos jovens masculinos, continha os ossos longos agrupados e os crânios colocados acima, e alguns adornos, como colares e contas. Destaca-se ainda o sepultamento 3, do tipo secundário, contendo os ossos de uma criança de cinco anos, que apresentou a datação mais antiga do sítio (Martin, 1994, 1995-1996).

Pelas informações ora apresentadas, vê-se que, embora sejam menos frequentes em comparação aos enterramentos primários, as evidências de práticas funerárias do tipo secundário se mostram distribuídas em várias regiões do Brasil e desde tempos muito antigos na pré-história brasileira, qualquer que seja a sua tipologia relacionada à subsistência dos grupos responsáveis. Com diferenças nos modos e no tratamento dos corpos e depósitos, os grupos humanos teriam realizado esse tipo de prática funerária de forma relativamente ampla e estendida, ainda que os processos ativos de redução do corpo sejam mais difíceis de reconhecer e menos comuns. Nesse sentido, um novo achado em um sítio arqueológico do Nordeste brasileiro, na Pedra do Cachorro (Buíque, Pernambuco), soma-se aos já existentes para gerar novas e mais detalhadas informações sobre este particular comportamento mortuário durante o Holoceno no Brasil.

\section{PEDRA DO CACHORRO NO CONTEXTO ARQUEOLÓGICO REGIONAL}

O sítio arqueológico conhecido como Pedra do Cachorro foi descoberto em 2010, quando alguns ossos humanos começaram a aflorar em superfície e foram coletados assistematicamente por habitantes da localidade, que acionaram o Instituto do Patrimônio Histórico e Artístico Nacional em Pernambuco (IPHAN-PE). O estudo preliminar em laboratório do esqueleto humano parcialmente completo mostrou a presença de chamativas marcas de corte e fraturas do tipo intencional antrópico (Solari et al., 2015). Tal achado motivou a realização de trabalhos de prospecção e escavação arqueológicas pela primeira vez no local em 2015, feitos por uma equipe do Departamento de Arqueologia, da Universidade Federal de Pernambuco (UFPE), com o apoio do Instituto Nacional de Ciência e Tecnologia de Arqueologia, Paleontologia e Ambiente do Semiárido do Nordeste do Brasil (INAPAS), objetivando caracterizar o potencial do sítio e contextualizar cronoestratigraficamente os achados.

A Pedra do Cachorro localiza-se no município de Buíque, Pernambuco, a 295 km da capital Recife (Figura 1). O sítio está inserido em uma mesorregião do agreste pernambucano, na transição entre o agreste e o sertão, no interior do Parque Nacional do Catimbau, administrado pelo Instituto Chico Mendes de Conservação da Biodiversidade (ICMBio), na coordenada UTM 24L 692959E - 9051647N (WGS-84), defronte à serra de Jerusalém. 


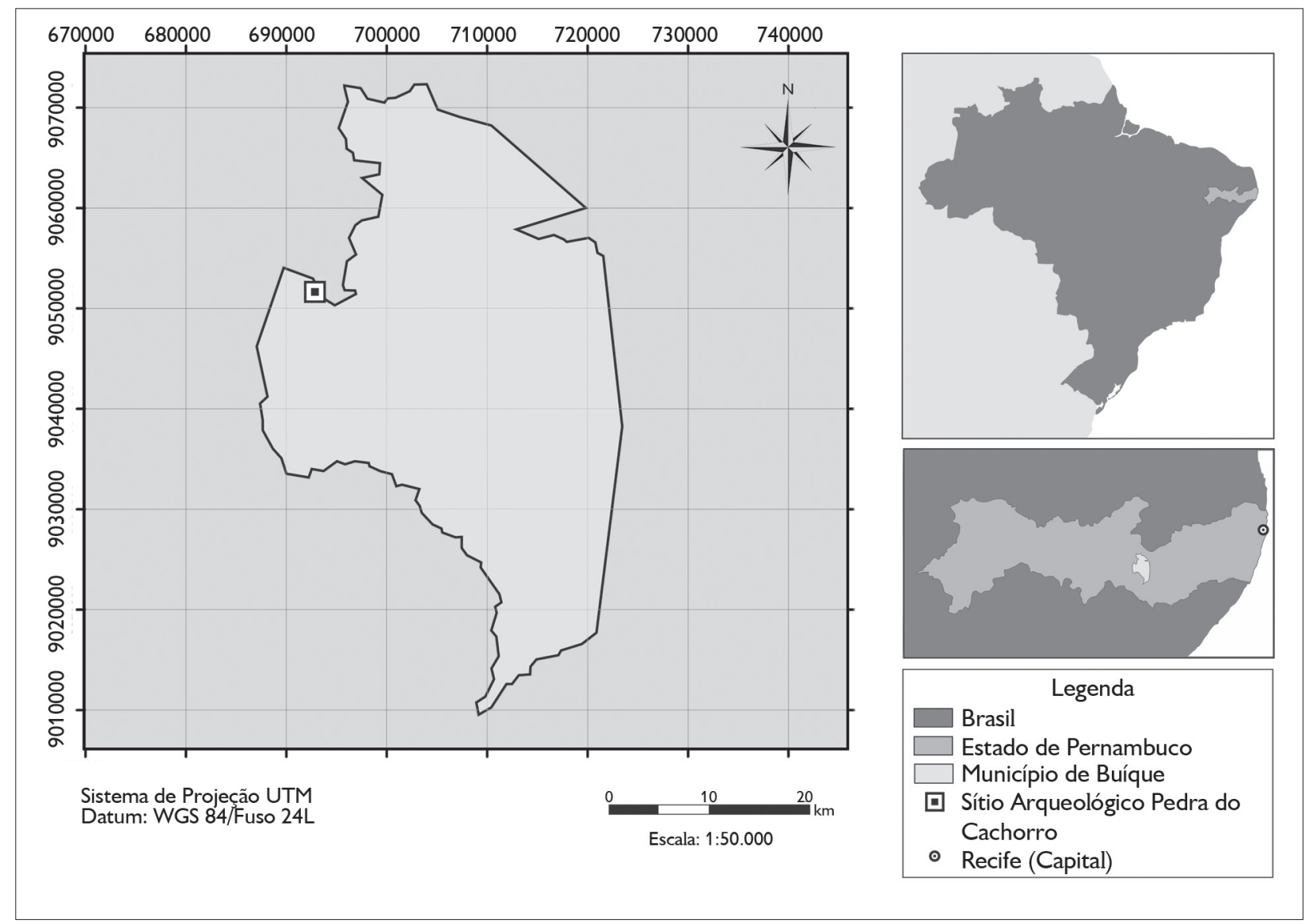

Figura 1. Mapa com a localização do sítio arqueológico Pedra do Cachorro, Buíque, Pernambuco. Fonte: Laboratório de Arqueologia Biológica e Forense (LABIFOR), Departamento de Arqueologia, UFPE.

O sítio arqueológico encontra-se em um abrigo, na lateral oeste de um afloramento rochoso homônimo, dada sua semelhança ao perfil de um cão. Sua área abrigada, semicoberta, mede aproximadamente $350 \mathrm{~m}^{2}$ e está sendo objeto de trabalhos arqueológicos. A partir da localização e da escavação - até o momento - de três sepultamentos humanos, apresenta potencial como espaço de uso funerário na região (Figura 2).

O Parque Nacional do Catimbau e entorno do sítio apresentam numerosos abrigos rochosos, onde foram identificados sítios arqueológicos com pinturas e gravuras rupestres, além de outras evidências de ocupação préhistórica, chegando a ser considerado o segundo maior parque arqueológico do país, depois do Parque Nacional
Serra da Capivara (Piauî). Na área, foram identificados cerca de 30 sítios arqueológicos, que oferecem informações sobre as ocupações pré-históricas da região, com amplos horizontes culturais e temporais, muitos dos quais associados com a tradição rupestre Agreste, difundida no Nordeste (Albuquerque; Lucena, 1991; Martin, 2005; Oliveira, 2006).

As evidências de ocupações humanas por grupos caçadores-coletores durante o Holoceno no vale de Catimbau concentram-se principalmente nas covas e nos abrigos areníticos, com datações compreendidas entre 6.000 e 2.000 A.P. Os sepultamentos localizados no sítios da região (Alcobaça, Gruta do Padre, Furna do Estrago, Cemitério do Caboclo, Peri-Peri ou Morro do Osso, entre outros) mostram a variabilidade do padrão funerário,

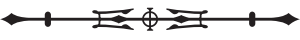




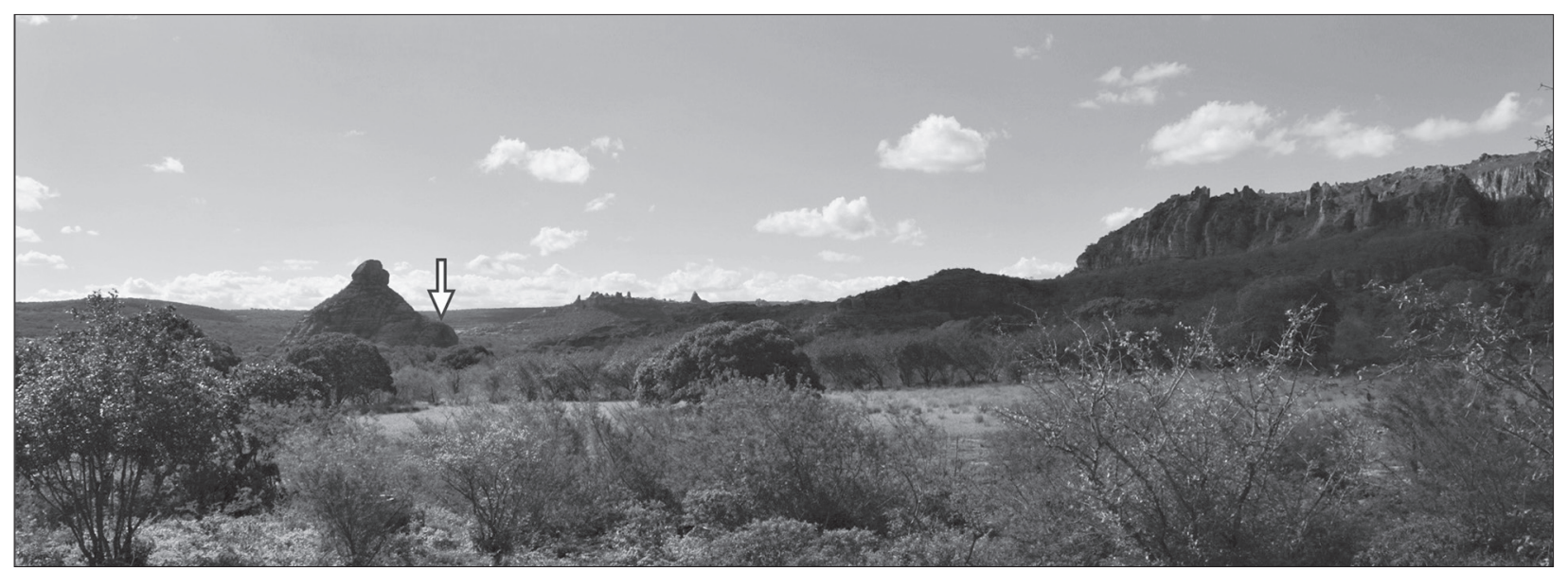

Figura 2. Inserção do abrigo Pedra do Cachorro na paisagem regional do vale de Catimbau. Foto: Laboratório de Arqueologia Biológica e Forense (LABIFOR), Departamento de Arqueologia, UFPE.

com presença de inumações e cremações, sepultamentos primários e secundários, com os corpos e membros depositados em variadas posições e orientações, com ou sem acompanhamentos funerários, incluindo diversos tipos de materiais associados, com e sem presença de pigmentos corporais etc. (Albuquerque; Lucena, 1991; Castro, 2009; Cisneiros, 2004; Martin, 2005; Oliveira, 2006). Nesse contexto, o abrigo rochoso Pedra do Cachorro insere-se como um novo sítio da região com presença de sepultamentos humanos primários e secundários datados - até o momento - entre $2.070^{1}$ a 760 A.P.

\section{O SEPULTAMENTO 1 DO SÍTIO PEDRA DO CACHORRO}

A escavação arqueológica na área onde havia surgido os ossos humanos - que inicialmente foram coletados de forma assistemática - permitiu a recuperação dos ossos restantes do mesmo indivíduo, os quais ainda estavam enterrados no local, e, afortunadamente, possibilitou o registro de parte da deposição funerária in situ, sem perturbações tafonômicas naturais ou antrópicas modernas.
Durante o trabalho de campo, foi constatado um agrupamento de ossos humanos desordenados, desarticulados, fraturados, com ausência de elementos ósseos (vértebras, ossos de mãos e pés), que se acharam concentrados em uma área aproximada de 40 $\mathrm{cm}$ de diâmetro e $30 \mathrm{~cm}$ de profundidade. $O$ conjunto ósseo apresentava claros indícios de intencionalidade no tratamento e na formação da deposição funerária. Esse achado permitiu confirmar que estávamos diante de um sepultamento em cova do tipo secundário ou composto (Duday et al., 1990; Duday, 2009a, 2009b; Schroeder, 2001; Sprague, 2005), contendo os remanescentes ósseos de um único indivíduo adulto masculino, com claros sinais de manipulação intencional humana (Binford, 1981; Botella et al., 2000; White, 1992), sem acompanhamentos mortuários ou estruturas funerárias associadas, o qual apresentou uma antiguidade de $760 \pm 30$ A.P. ${ }^{2}$, pelo método de datação direta a partir de colágeno extraído em osso, com a técnica de Espectrometria de Massas com Aceleradores (AMS) (Figura 3).

A datação de $2.070 \pm 30$ A.P foi feita em carvões associados ao sepultamento primário de uma criança (sepultamento 2), mas ainda vai ser feita uma datação direta em osso, para confirmar a antiguidade do sepultamento.

2 Beta-424624: idade radiocarbônica medida: $640 \pm 30$ A.P.; idade radiocarbônica convencional: $760 \pm 30$ A.P.; calibração (2 sigma): Cal A.D. 1265 a 1305 (Cal A.P. 685 a 645) e Cal A.D. 1365 a 1375 (Cal A.P. 585 a 575).

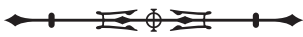




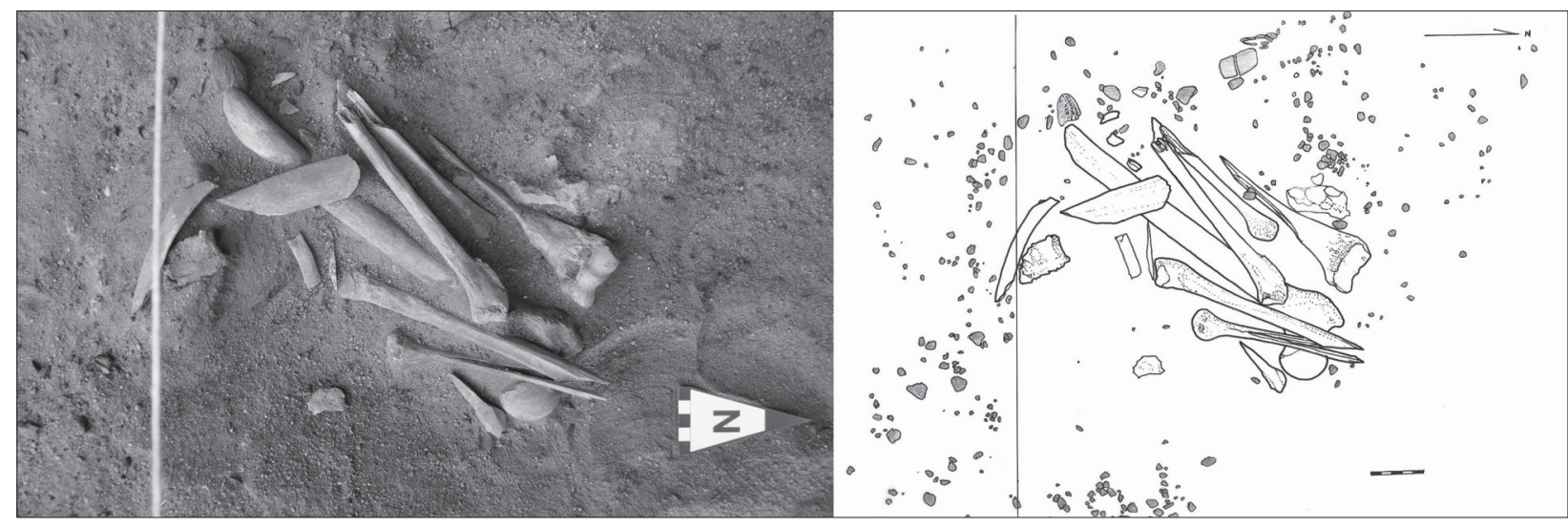

Figura 3. Parte do contexto secundário, in situ, do sepultamento 1 com sinais de manipulação intencional. Foto e desenho: Laboratório de Arqueologia Biológica e Forense (LABIFOR), Departamento de Arqueologia, UFPE.

Logo após a curadoria, o inventário e a análise bioarqueológica em laboratório dos remanescentes humanos do sepultamento 1, pudemos verificar que se trata de um esqueleto parcialmente completo de um único indivíduo adulto, com idade aproximada entre 35 e 45 anos, de acordo com os métodos de estimação de idade em adultos ${ }^{3}$ da quarta costela (Loth; Iscan, 1989) e da sinostose das suturas cranianas (Masset, 1989; Meindl; Lovejoy, 1985); de sexo masculino, por características morfológicas do crânio e da pélvis (Bass, 2005; Buikstra; Ubelaker, 1994; Ferembach et al., 1979; Ubelaker, 1989; White; Folkens, 2005); de afinidade biológica indígena americana (Bass, 2005; Gill, 1998); e uma estatura aproximada de 1,63 m (Genovés, 1967; Bass, 2005). Também foi possível observar que, fundamentalmente, o esqueleto destaca-se por apresentar uma série de sinais de manipulação intencional perimortem ou em ossos frescos, incluindo marcas de corte, fraturas, golpes e esmagamento (Botella et al., 2000; Binford, 1981; White, 1992), vinculadas à prática mortuária de um sepultamento secundário, com descarnamento ativo do cadáver.

\section{A METODOLOGIA DE IDENTIFICAÇÃO DE SINAIS DE MANIPULAÇÕES INTENCIONAIS}

Os atributos selecionados para análise das modificações intencionais foram observados macroscopicamente em cada espécime ósseo, e se centraram na identificação, na preservação e no registro dos sinais de manipulação: fraturas, marcas de corte, golpes e esmagamento. Para tal análise, foi utilizada uma adaptação dos critérios metodológicos propostos por White (1992), Binford (1981) e Botella et al. (2000), integrando técnicas e métodos de análise e observação da zooarqueologia, da antropologia física/ biológica e da tafonomia, o que resulta em uma aproximaç̧ão mais adequada para o estudo de sinais de manipulações intencionais em ossos humanos e/ou de animais.

\section{FRATURAS}

Entendemos as fraturas como a perda de continuidade da substância óssea (Adams, 1974; Compere et al., 1959; De Palma, 1966). De acordo com a etiologia, podem ser produzidas por um traumatismo brusco, por fadiga, por sobrecarga repetida e/ou por patologias ósseas. Nos casos

3 Os métodos de estimação de idade para indivíduos adultos têm menor margem de precisão porque se baseiam na degeneração do esqueleto e, portanto, estão sujeitos à variabilidade individual e ambiental, ao contrário dos métodos para estimação de idade em indivíduos subadultos, baseados na maturação do esqueleto ou na calcificação e erupção dentária, sujeitos a condições genéticas. Neste caso, o método de Loth e Iscan (1989) apresenta uma margem de erro crescente e significativa a partir da segunda década de vida. Da mesma forma, a sinostose das suturas cranianas (Masset, 1989; Meindl; Lovejoy, 1985) está sujeita a uma grande variabilidade individual, devendo ser usada com cuidado.

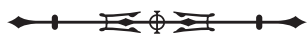


de traumatismo brusco, são provocadas pela aplicação de uma força que excede os limites da resistência do osso. As forças que produzem as fraturas podem ser diretas ou indiretas: a força direta resulta do impacto, enquanto as forças indiretas são produzidas por mecanismos de torção, tração ou flexão. $\bigcirc$ tipo de fratura está determinado pela direção e pela violência causal, além da intensidade dessa força. Outros fatores intrínsecos que influenciam são a idade do indivíduo, a resistência do osso e a sua natureza (se compacto ou esponjoso). As fraturas se designam mediante termos descritivos segundo a forma da superfície fraturada.

Com respeito ao problema de diferenciar os agentes responsáveis pela fratura, humanos ou não humanos, é importante reforçar que o tipo de fratura não identifica o agente causador. Múltiplos agentes podem produzir o mesmo padrão de fratura, incluindo os casos da morfologia espiralada, que podem ser tanto o resultado da ação humana, como de outros fatores ou agentes tafonômicos naturais, abarcando mordeduras de animais carnívoros, exposição à intempérie ou pisoteio de animais (Agenbroad, 1989; Binford, 1981; Haynes, 1983; Hill, 1976; Myers et al., 1980; White, 1992). O que melhor permite reconhecer o ser humano como agente responsável é a observação de marcas deixadas por instrumentos (líticos, metálicos etc.) utilizados para produzir a fratura intencional do osso, também o reconhecimento de um padrão de dano intencional do osso, não aleatório e diferente de outros fatores ou agentes não humanos.

Quanto à antiguidade da fratura, o principal interesse está em distinguir aquelas que são perimortem, ou produzidas em ossos frescos, ou seja, contendo substância orgânica (colágeno), daquelas que foram produzidas postmortem em ossos secos e sem conteúdo orgânico (Turner II; Turner, 1990; Sauer, 1998; Villa; Mahieu, 1991; Ubelaker; Adams, 1995; Wieberg; Wescott, 2008). Apesar de que, em alguns casos, essa distinção possa ser problemática - em particular, em ossos planos e com pouca espessura cortical, como do quadril, costelas e escápulas -, geralmente não resulta difícil para o olhar de um observador treinado. Assim, os tipos de morfologia da fratura, sua coloração e textura superficial resultam diferentes umas das outras quando se trata de ossos frescos e secos (Botella et al., 2000; Larsen, 1997; Walker, 2001; White, 1992).

Segundo Larsen (1997) e Walker (2001), é fundamental para a interpretação do trauma observado o reconhecimento a respeito do traumatismo, se foi sofrido antes da morte (antemortem), próximo ao momento da morte (perimortem) ou depois da morte (postmortem). Para estes autores, as fraturas antemortem são as únicas que apresentam sinais de remodelação óssea, geralmente em forma de um calo de osso novo que se cria ao redor da fratura, e que persiste durante muito tempo depois de que se produziu o traumatismo. Pelo contrário, as fraturas perimortem e postmortem não apresentam sinais de remodelação óssea e se diferenciam entre si, basicamente, pela tipologia e, às vezes, pela coloração. As fraturas perimortem produzidas em ossos frescos apresentam as mesmas características que os sujeitos vivos, enquanto as fraturas postmortem, feitas em ossos em estado seco, são comumente ocasionadas por processos pós-deposicionais ou durante a escavação. Igualmente, é importante esclarecer que no que concerne a fraturas perimortem em ossos frescos, pode ser impossível determinar, com precisão, se as mesmas ocorreram pouco antes da morte, no momento ou pouco tempo depois, tendo em conta que os ossos podem permanecer 'frescos' durante muito tempo depois da morte, inclusive anos, dependendo do ambiente deposicional, e não propriamente do tempo transcorrido (Lyman; Fox, 1989).

\section{CORTES}

A discussão sobre o reconhecimento de marcas de corte em superfícies ósseas é de longa data dentro da comunidade acadêmica arqueológica e paleontológica internacional. Principalmente durante as décadas de 1980 e 1990, esteve ligada à identificação da ação humana como responsável pelas marcas encontradas em ossos 
de animais, para inferir a origem de atividades de caça e processamento em nossos ancestrais hominídeos do continente africano (Binford, 1981; Bunn; Kroll, 1986; Bunn et al., 1980; Lupo; O'Connel, 2002; Potts; Shipman, 1981; Selvaggio, 1994; Shipman; Rose, 1983).

A questão aqui, como no caso das fraturas, é que, muitas vezes, identificar o agente humano como o responsável pelos sinais observados nas superfícies ósseas não é tão simples, uma vez que, também nestes casos, vários agentes tafonômicos (carnívoros, roedores, abrasão, pisoteio de animais, raízes, entre outros) podem ocasionar alterações na superfície óssea semelhantes às marcas de cortes intencionais, produzidas por diversos instrumentos de corte (Behrensmeyer et al., 1986; Binford, 1981; Bunn, 1981; Olsen; Shipman, 1988; Potts; Shipman, 1981; Shipman; Rose, 1983, 1984; Walker; Long, 1977; White, 1992).

Nessa mesma época, alguns autores sugeriram que a solução para o diagnóstico das marcas de corte estava em se fazer uma abordagem com o uso de microscópio de varredura eletrônica (Scanning Electron Microscope - SEM) (Potts; Shipman, 1981; Shipman; Rose, 1983. 1984), enquanto outros consideravam que a observação macroscópica era suficiente para seu reconhecimento (Binford, 1981; Bunn, 1981, 1991; Bunn; Kroll, 1986; Lupo; O'Connell, 2002; Selvaggio, 1994; White, 1992). Na realidade, o que esses autores procuravam apontar era que, mais importante do que o reconhecimento individualizado das marcas por suas propriedades formais de uma única marca discreta, o modo mais apropriado para a identificação de agentes humanos reside na percepção das características gerais definidoras dos sinais de corte em si mesmas e, principalmente, na compreensão do padrão geral de danos observáveis na superfície óssea, a partir da localização e da distribuição dos mesmos, a fim de inferir a respeito das atividades relacionadas (Binford, 1981; White, 1992). Por isso, consideramos que, para o reconhecimento de marcas de corte, resulta adequado fazer uso da seguinte definição de Haynes e Stanford (1984, p. 226 apud White, 1992, p. 145):
Cut marks should be found on parts of bones where a sharp edge would have been necessary to separate meat from bone, bone from bone, or hide from carcass. Cut marks should be clean incisions with $\vee$-shaped cross sections. True cut marks should be discontinuous or conformable on bone surfaces where the topography is uneven, because inflexible tool edges skip over minor depressions when applied to bone surfaces. It must be kept in mind that cut marks are the result of plausible, practical human motor actions such as sawing, scraping, or slicing. Most butchering cut marks are sets of a few short, parallel, linear incisions.

Ao mesmo tempo, a distribuição e a localização das marcas de corte sobre o relevo ósseo superficial, conforme suas características anatômicas, são fundamentais para identificação das atividades responsáveis em gerar esses sinais, ou seja: esfolamento, descarnamento, desarticulação e raspagem (Botella et al., 2000).

Neste sentido, conforme Botella et al. (2000), as marcas de esfolamento trata-se de sinais que ficam registrados no osso como consequência do corte da pele para separá-la do resto do corpo. Por ser um tipo de marca que só é observável quando a pele está em proximidade com o osso, é no crânio onde se apreciam as marcas mais claras, que se consideram do esfolamento. Além do que, o esfolamento do esqueleto pós-craniano normalmente deixa poucos sinais, já que é possível retirar a pele com poucos cortes, e sem afetar o osso. A maioria das marcas de esfolamento que se encontram no crânio é observada como incisão fina e retilínea, de comprimento variável. Varia também em termos de profundidade e espessura, dependendo do instrumento utilizado durante o procedimento. Naquelas zonas do crânio com morfologia irregular e maior número de ligamentos e músculos, tais incisões tendem a ser múltiplas e irregulares.

Os sinais de desarticulação, segundo Botella et al. (2000), são as incisões que ficam marcadas nos ossos como consequência do corte das partes moles, para separar diferentes segmentos corporais pelas articulações ou juntas. Para serem consideradas como tais, deve-se sempre observar as zonas periarticulares; localizadas nas epífises

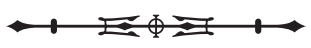


dos ossos longos, próximo da borda articular ou nas regiões correspondentes às inserções musculares. A desarticulação procura conseguir a separação dos membros corporais nas articulações, e realiza-se por meio de cortes, ainda que também se possa aplicar tração, rotação e golpes, quando resulta ser difícil acessar, com o instrumento cortante, a zona articular para deslocar as partes. As marcas de desarticulação consistem frequentemente em incisões transversais, paralelas à superfície articular e perpendiculares ao eixo maior do osso. Podem ser únicas e longas, ou múltiplas e curtas, sempre com secção em ' $V$ '. A espessura e a profundidade variam de acordo com o tipo de instrumento empregado e o ângulo do fio. Também afetam sua morfologia a força aplicada no corte e a articulação do esqueleto em questão.

Por sua vez, o descarnamento, para Botella et al. (2000), é o processo de extração das massas musculares. As marcas de descarnamento resultam como consequência do corte das partes moles, quando o fio do instrumento se apoia sobre o osso, e deixa a sua marca em forma de incisões. Podem localizar-se em qualquer segmento do osso, exceto nas zonas articulares. Trata-se de incisões lineares, que mostram uma seção em ' $\mathrm{V}$ ', com uma profundidade e espessura variável, de acordo com o tipo de instrumento e a força empregada no corte. Esses autores propõem que o interesse da manobra reside na retirada da carne, e não em marcar o osso, por isso as marcas se encontram geralmente aí, onde o gume do instrumento golpeia contra o osso, naquelas regiões que sobressaem conforme a morfologia geral do osso ou onde o músculo se estreita e há menos cobertura por tecidos moles. Também, normalmente, o corte da carne se realiza insistindo sobre a massa muscular, até conseguir finalmente separá-la de seu suporte ósseo, pelo qual as marcas de descarnamento tendem a ser múltiplas e paralelas, dispostas em sentido perpendicular ou longitudinal na mesma direção e escalonadas.

Por último, as marcas de raspagem, Botella et al. (2000), caracterizam-se por estrias numerosas, de traço irregular, identificadas sobre a superfície externa de algumas porções de ossos. São produzidas, fundamentalmente, pela remoção do periósteo, ou pela limpeza das áreas com inserções musculares e ligamentosas, especialmente amplas e fortemente aderidas. Os sinais consistem em conjuntos de finas marcas lineares e múltiplas, com secções em ' $V$ ', rasas e pouco extensas. São observadas agrupadas, inclusive sobrepostas e entrecruzadas, denotando a repetição do gesto no mesmo lugar.

\section{GOLPES}

Considerando, que morfologicamente, os sinais de golpes são equivalentes às marcas de percussion pits (White, 1992, p. 139) e chop marks (White, 1992, p. 146), estes dois tipos de marcas foram agrupados pela sua similitude morfológica, apesar de sua funcionalidade diferencial. Conforme White (1992), elas são produzidas em ações de percussão e ocorrem quando um instrumento cortante ou curto-contundente é usado para golpear perpendicularmente a superfície óssea. A morfologia das chop marks e as percussion pits são as mesmas, sendo indistinguíveis morfologicamente. A distinção que o autor faz entre elas é de acordo com sua funcionalidade. No caso das percussion pits, o objetivo dos golpes é fraturar o osso e, geralmente, as marcas são observadas nas proximidades das bordas das fraturas; já no caso das chop marks, o objetivo dos golpes é a remoção dos tecidos moles.

\section{ESMAGAMENTO}

O último dos critérios avaliados foi o fato descrito por White (1992) como esmagamento (crushing), referindo-se ao esmagamento ou deslocamento do osso cortical para o interior do espaço ocupado pelo osso esponjoso. Esse fenômeno ocorre, geralmente, nas áreas metafisárias articulares de ossos longos, ainda que também possa ser observado em ossos de crânio ou do esqueleto axial. É um dos vários critérios apontados por White (1992) relacionados com os produtos de fraturas por percussão, que ajudam no reconhecimento dessa atividade. 


\section{RESULTADOS: AS MANIPULAÇÕES NO SEPULTAMENTO 1}

A partir dessa proposta metodológica, foi possível observar que os ossos do sepultamento 1 mostraram os seguintes sinais de trauma ou manipulação intencional do tipo perimortem: fraturas, marcas de corte (esfolamento, descarnamento, desarticulação e raspagem), golpes e esmagamento, como pode ser representado de forma esquemática na Figura 4 e ilustrado nas Figuras 5,6 e 7 .
No esqueleto do sepultamento 1, foi possível observar que o crânio, a maioria dos ossos longos e as costelas estavam fraturados, enquanto alguns ossos, como ulnas, rádios e ossos dos quadris, achavam-se completos e sem fratura. A maioria dos ossos quebrados apresentava características morfológicas das fraturas do tipo perimortem em ossos frescos, produzidas por percussão e vinculadas ao processo redutivo in situ dentro da prática funerária secundária, na sua etapa final de deposição no local de enterramento definitivo (Figura 5). Ao comparar com

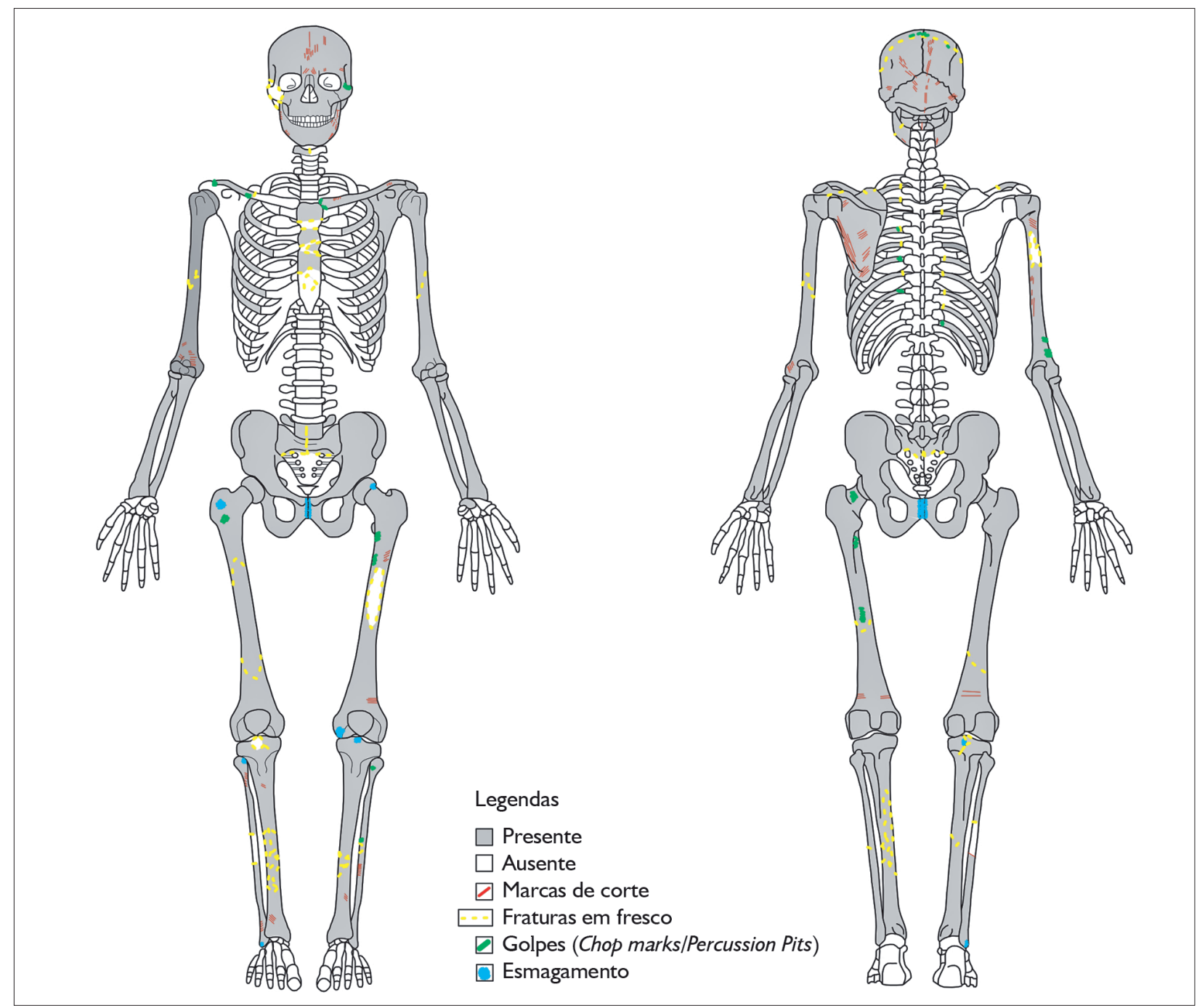

Figura 4. Esquema dos ossos presentes e os sinais de manipulação intencional identificados no esqueleto do sepultamento 1. Fonte: Laboratório de Arqueologia Biológica e Forense (LABIFOR), Departamento de Arqueologia, UFPE.

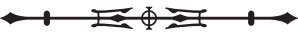


outros sítios arqueológicos, vemos que Lapa das Boleiras (Neves et al., 2002), Lapa do Santo (Strauss, 2010, 2014, 2016) e Lapa do Caboclo (Solari et al., 2012) também mostraram padrões similares de fratura intencional dos ossos como parte das práticas funerárias em contextos de sepultamentos secundários.

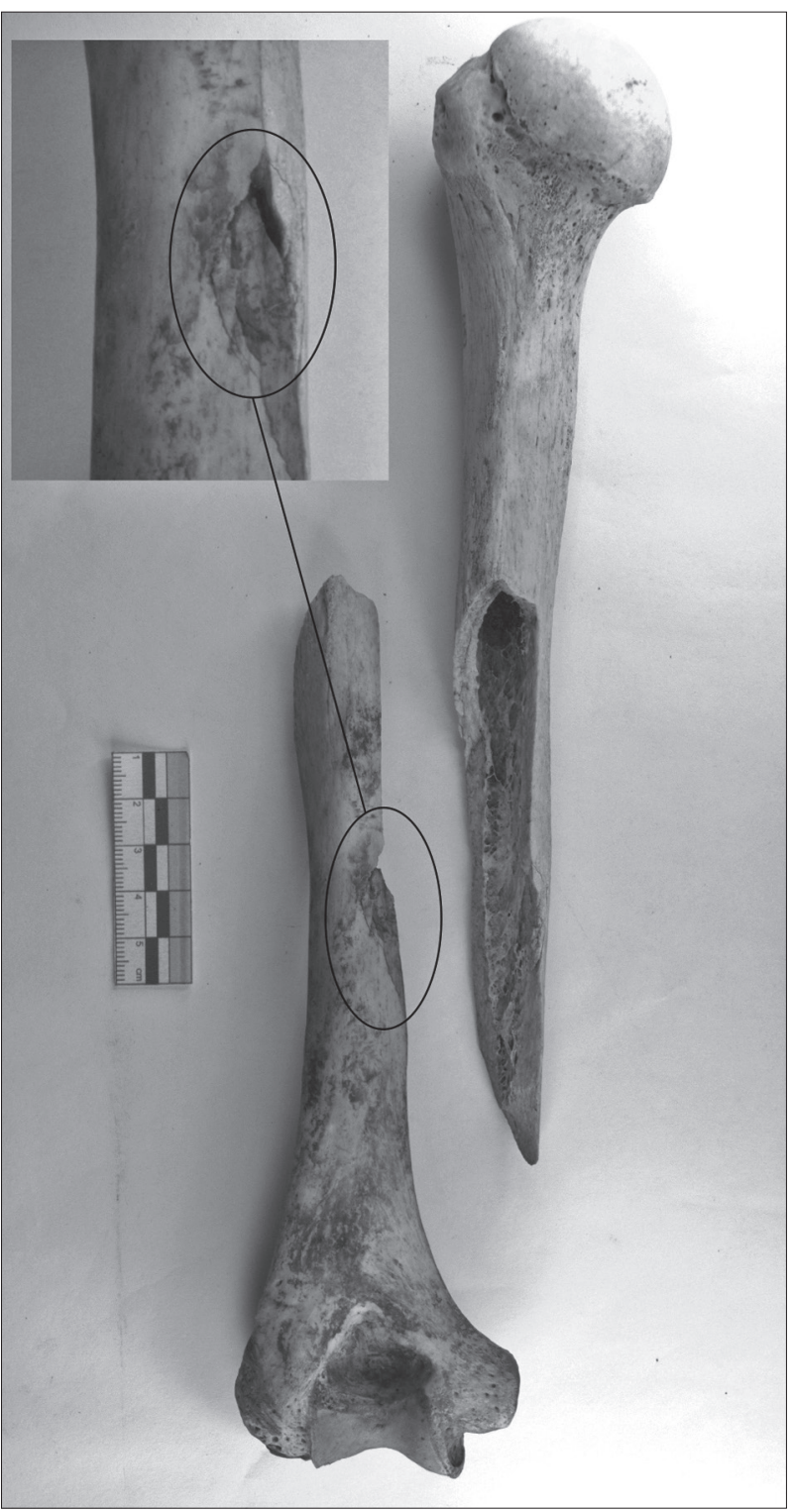

Figura 5. Úmero com fratura fresca (perimortem) e detalhe do ponto de impacto por percussão. Escala: $5 \mathrm{~cm}$. Foto: Laboratório de Arqueologia Biológica e Forense (LABIFOR), Departamento de Arqueologia, UFPE.
Por outra parte, os mesmos ossos do sepultamento 1 que apresentaram fraturas perimortem também exibiram uma série de marcas longitudinais, retilíneas e paralelas sobre a superfície cortical externa, sendo classificadas como marcas de corte intencionais. Por sua morfologia e localização, foram identificados sinais de cortes resultantes de atividades de esfolamento e raspagem no crânio e na mandíbula, assim como ações de desarticulação e descarnamento de alguns ossos do esqueleto póscraniano, produto de um descarnamento ativo do cadáver em uma etapa inicial, vinculada a acelerar o processo de decomposição/redução do cadáver e ajudar na limpeza do esqueleto dentro da prática funerária secundária (Figura 6).

Todavia, ao comparar o sepultamento 1 de Pedra do Cachorro com outros sítios arqueológicos, somente o padrão 2 de Lapa do Santo (Strauss, 2010, 2014, 2016) apresentou um registro inquestionável de marcas de corte em alguns de seus sepultamentos secundários com manipulação intencional dos cadáveres. No entanto, não descartamos que outros sítios pré-históricos brasileiros

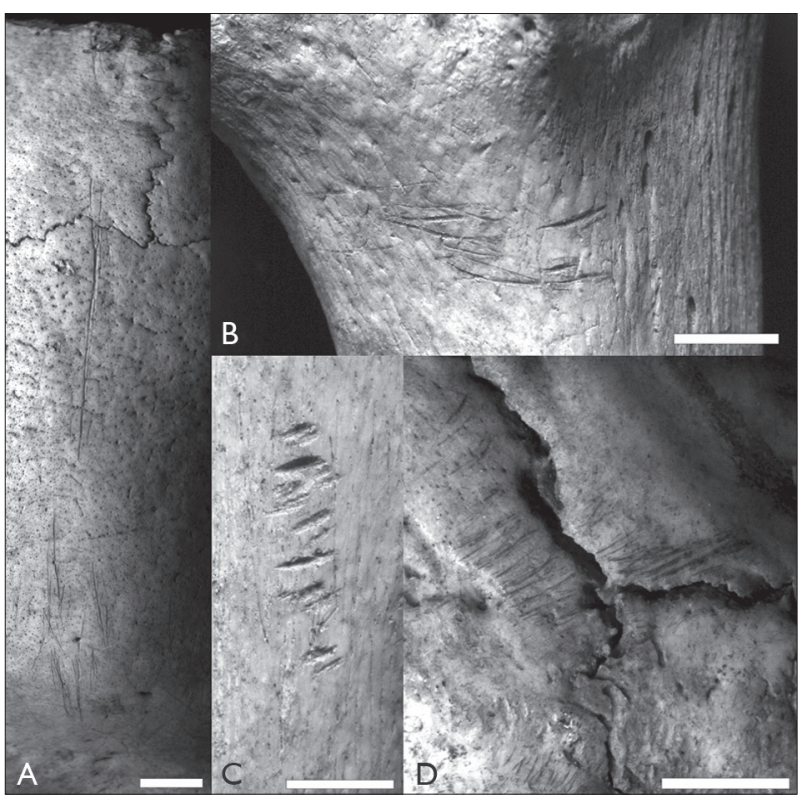

Figura 6. Tipos de marcas de corte observadas no sepultamento 1: A) esfolamento; B) desarticulação; C) descarnamento; D) raspagem. Escalas: $1 \mathrm{~cm}$. Fonte:Laboratório de Arqueologia Biológica e Forense (LABIFOR), Departamento de Arqueologia, UFPE.

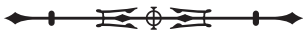




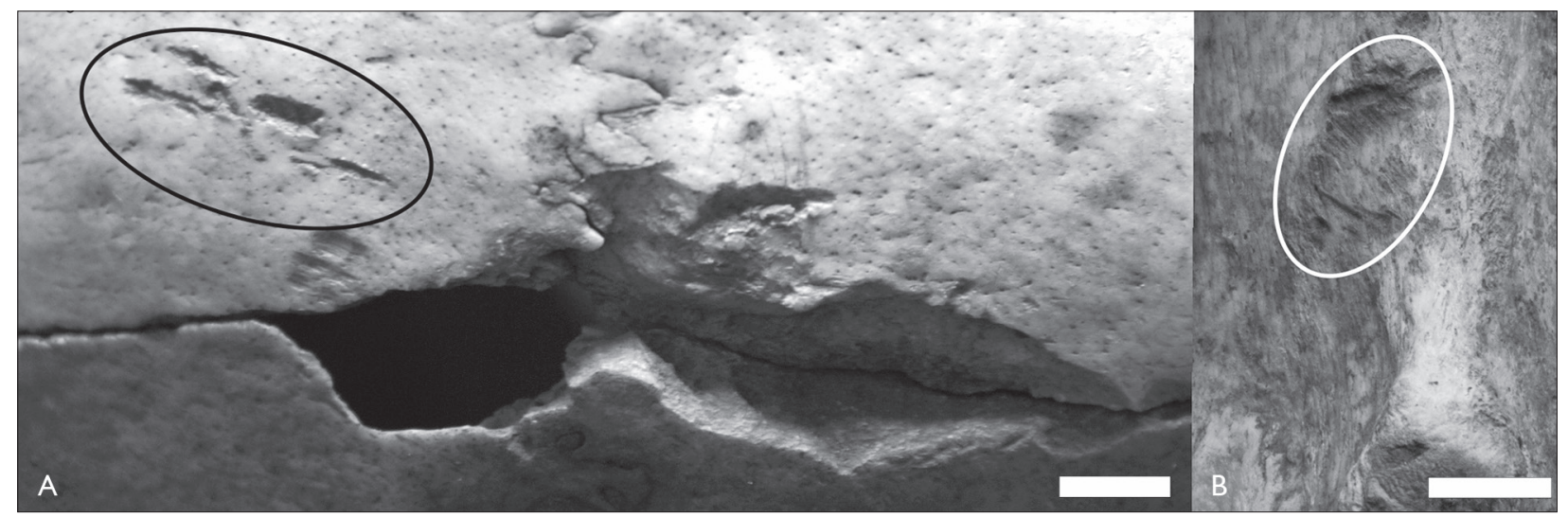

Figura 7. Tipos de golpes observados no sepultamento 1: A) percussion pits; B) chop marks. Escalas: 1 cm. Fonte: Laboratório de Arqueologia Biológica e Forense (LABIFOR), Departamento de Arqueologia, UFPE.

com sepultamentos secundários já escavados poderiam também conter marcas de corte, mas que talvez não tenham sido examinadas por especialistas e simplesmente passaram desapercebidas pelos arqueólogos.

Ao mesmo tempo, na maioria dos ossos do sepultamento 1 com sinais de fraturas e cortes, foi observada uma série particular de marcas com seção mais ampla e profunda do que as marcas de corte, que foi identificada como golpes - incluindo as duas funções das percussion pits e chop marks segundo White (1992) - para remover os tecidos moles na limpeza do esqueleto e fraturar os ossos na conformação da deposição final (Figura 7).

Por último, no esqueleto do sepultamento 1 , foi possível observar sinais de esmagamento em alguns ossos (White, 1992), vinculados com a desarticulação do corpo e associados às fraturas por percussão como parte do tratamento funerário (Figura 8).

\section{CONSIDERAÇÕES FINAIS}

As práticas funerárias referem-se às ações realizadas na preparação do cadáver e no destino final do corpo, de acordo com a maneira como determinado grupo enfrenta o fenômeno da morte dos seus próprios membros. Analisar os contextos mortuários em um sítio arqueológico e tentar reconstruir as etapas do ritual funerário (tratamento do cadáver, local e forma do enterramento, uso de

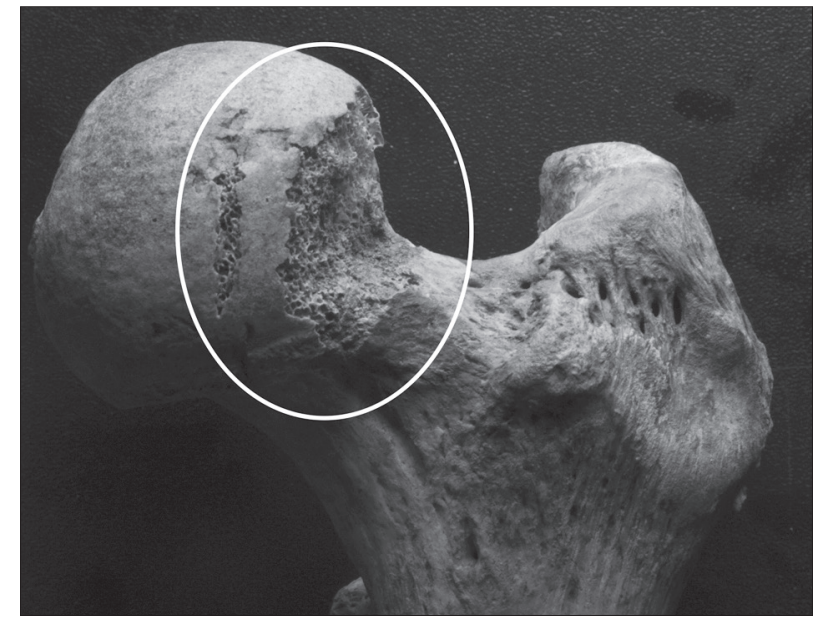

Figura 8. Fêmur com sinais de esmagamento. Fonte:Laboratório de Arqueologia Biológica e Forense (LABIFOR), Departamento de Arqueologia, UFPE.

acompanhamentos funerários etc.) são modos de nos aproximar dos aspectos simbólicos, culturais, sociais e ideológicos vinculados com a morte nos grupos estudados, pelo fato de que tais práticas transmitem e comunicam crenças, valores, identidades, tradições e memórias do grupo em questão.

Mesmo em uma proporção menor do que os sepultamentos primários, os enterramentos secundários caracterizam-se como resultantes de práticas funerárias relativamente comuns e estendidas entre as populações pré-históricas brasileiras. A disposição dos ossos em

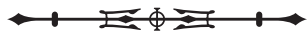


feixes, o uso de pigmento ocre-avermelhado e os ossos queimados têm sido indicadores desse tipo de prática, a qual parece vincular-se a uma decomposição natural do cadáver na maioria dos casos ou que não deixou marcas intencionais durante a redução dos corpos, no âmbito do ciclo funerário tradicional. Menos comuns são os casos de enterramentos secundários com descarnamento intencional ou outros tipos de manipulações corporais, como é o caso apresentado aqui no sepultamento 1 de Pedra do Cachorro, ou como nos outros casos mencionados dos sepultamentos dos sítios Lapa das Boleiras (Neves et al., 2002), Lapa do Santo (Strauss, 2010, 2014, 2016) e Lapa do Caboclo (Solari et al., 2012).

Ainda que em fase inicial das escavações no sítio arqueológico Pedra do Cachorro, o achado deste sepultamento e as manipulações intencionais perimortem que os ossos exibem ajudam a conhecer melhor a variabilidade dos rituais funerários das sociedades passadas no Brasil.

Com o uso de uma metodologia adequada para o reconhecimento de manipulações intencionais antrópicas, no esqueleto do sepultamento 1 , foram identificadas marcas de corte, resultado de atividades de esfolamento e raspagem no crânio e na mandíbula, assim como desarticulação e descarnamento em muitos dos ossos longos. Também foram observadas marcas de golpes intencionais com duas finalidades, para fraturar os ossos e para remoção de tecidos moles, assim como alguns sinais de esmagamentos, associados às desarticulações do corpo e às fraturas por percussão. Todas estas marcas e as atividades associadas estariam vinculadas a um descarnamento ativo para ajudar e/ou acelerar o processo de putrefação do cadáver, em uma primeira etapa do ritual funerário secundário.

Além disso, o esqueleto do sepultamento 1 apresentou a maioria dos ossos quebrados intencionalmente, mostrando características e morfologias próprias de fraturas perimortem ou em ossos frescos, e sinais de golpes e esmagamentos associadas às fraturas por percussão. Nesse caso, foi possível inferir que a fraturação dos ossos esteve vinculada à conformação do depósito final dos remanescentes na última etapa do ritual funerário, que resultou na sua deposição secundária.

Por sua parte, o contexto arqueológico desses remanescentes ósseos in situ permitiu observar: a completa ausência de conexão anatômica entre os ossos, um agrupamento dos mesmos de forma desordenada e uma ausência intencional de segmentos ósseos (faltavam as vértebras, assim como os ossos de mãos e pés).

Em suma, a observação das manipulações antrópicas intencionais sobre o esqueleto, associadas ao contexto arqueológico, permitiu definir o achado como um sepultamento secundário com ações de redução corporal e descarnamento ativo do cadáver, uma prática mais ou menos comum em contextos pré-históricos brasileiros, mas dificilmente observada mostrando tão claramente os sinais de manipulação nos ossos, como este caso em particular mostrou.

Por fim, coincidindo com as reflexões de Strauss (2010, 2016) para o sítio Lapa do Santo - além das diferenças na quantidade de sepultamentos e complexidade dos sítios -, cremos que também em Pedra do Cachorro, na ausência de estruturas funerárias sofisticadas ou ricos acompanhamentos mortuários, a prática dos sepultamentos secundários com sinais de manipulações intencionais dos cadáveres igualmente implica a elaboração de rituais complexos, nos quais os corpos teriam sido usados como símbolos, refletindo aspectos da própria cosmovisão daqueles grupos, por mais que a maioria desses significados fique inacessível para nós no presente.

\section{AGRADECIMENTOS}

Os autores agradecem o apoio institucional do Departamento de Arqueologia da Universidade Federal de Pernambuco (DARQ-UFPE) e o financiamento do Instituto Nacional de Ciência e Tecnologia de Arqueologia, Paleontologia e Ambiente do Semiárido do Nordeste do Brasil (INCT-INAPAS), especialmente à professora Dra. Gabriela Martin, por amparar e incentivar todas as nossas atividades de pesquisa no sítio. Em particular, Ana Solari

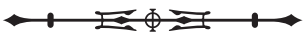


agradece ao Programa Nacional de Pós Doutorado da Coordenação de Aperfeiçoamento de Pessoal de Nível Superior (PNPD-CAPES), pela bolsa de pós-doutorado, na qual se insere esta pesquisa. Finalmente, os autores agradecem aos vários arqueólogos e alunos da UFPE que participaram das atividades arqueológicas em campo e em laboratório, pela ajuda e pela colaboração.

\section{REFERÊNCIAS}

ADAMS, J. C. Manual de fracturas y de lesiones articulares. Barcelona: Ediciones Toray, 1974.

AGENBROAD, L. D. Spiral fractured mammoth bone from nonhuman taphonomic processes at Hot Springs Mammoth site. In: BONNICHSEN, R.; SORG, M. H. (Ed.). Bone modification. Orono: Center for the Study of the First Americans, 1989. p. 139-147.

ALBUQUERQUE, M.; LUCENA, V. Caçadores-coletores no agreste pernambucano: ocupação e ambiente holocênico. CLIO - Série Arqueológica, Recife, n. 4, p. 73-75, 1991. Número extraordinário dedicado aos Anais de I Simpósio de Pré-história do Nordeste Brasileiro, Recife, 1987.

BALDUS, H. Bibliografia crítica da etnologia brasileira. São Paulo: Comissão do IV Centenário da Cidade de São Paulo, 1954.

BALDUS, H.; WILLEMS, E. Dicionário de etnologia e sociologia. São Paulo: Companhia Editora Nacional, 1939. (Biblioteca Pedagógica Brasileira, Série 4, v. 17).

BASS, M. W. Human osteology: a laboratory and field manual. Springfield: Missouri Archaeological Society, 2005.

BEHRENSMEYER, A. K.; GORDON, K. D.; YANAGI, G. T. Trampling as a cause of bone surface damage and pseudo-cutmarks. Nature, v. 319, p. 768-771, Feb. 1986.

BINFORD, L. R. Bones: ancient men and modern myths. New York: Academic Press, 1981

BOGGIANI, G. Viajes de un artista por la América meridional. Los Caduveos. Expedición al río Nabileque, en la región de las grandes cacerías de venados, Mato Grosso (Brasil). Revista del Instituto de Etnología de la Universidad Nacional de Tucumán, Tucumán, tomo I, p. 495-556, 1930.

BOTELLA, M. C.; ALEMÁN, I.; JIMÉNEZ, S. A. Los huesos humanos: manipulación y alteraciones. Barcelona: Ediciones Bellaterra, 2000.

BROWN, J. A. (Ed.). Approaches to the social dimensions of mortuary practices. Washington: Society for American Archaeology, 1971. (Memoir of the Society for American Archaeology, n. 25).
BUIKSTRA, J. E.; UBELAKER, D. H. (Ed.). Standards for data collection from human skeletal remains. Fayetteville: Arkansas Archeological Survey, 1994. (Research Series, n. 44).

BUNN, H. T. A taphonomic perspective on the archaeology of human origins. Annual Review of Anthropology, n. 20, p. 433467, Oct. 1991.

BUNN, H. T. Archaeological evidence for meat-eating by PlioPleistocene hominids from Koobi Fora and Olduvai Gorge. Nature, v. 291, p. 574-577, June 1981.

BUNN, H. T.; KROLL, E. M. Systematic butchery by Plio/Pleistocene hominids at Olduvai Gorge, Tanzania. Current Anthropology, Chicago, v. 27, n. 5, p. 431-452, Dec. 1986.

BUNN, H.; HARRIS, J.; ISAAC, G.; KAUFULU, Z.; KROLL, E.; SCHICK, K.; TOTH, N.; BEHRENSMEYER, A. Fxjj50: an Early Pleistocene site in northern Kenya. World Archaeology, v. 12, n. 2, p. 109-136, Oct. 1980.

CARNEIRO DA CUNHA, M. Os mortos e os outros. São Paulo: Editora Hucitec, 1978.

CARR, C. Mortuary practices: their social, philosophical-religious, circumstantial and physical determinants. Journal of Archaeological Method and Theory, EUA, v. 2, n. 2, p. 105-200, June 1995.

CASTRO, V. Marcadores de identidades coletivas no contexto funerário pré-histórico no Nordeste do Brasil. 2009. 310 f. Tese (Doutorado em Arqueologia) - Universidade Federal de Pernambuco, Recife, 2009.

CÉSAR, J. V. Enterros em urnas dos Tupi-guaranis. In: SCHADEN, E. (Ed.). Homem, cultura e sociedade no Brasil. Petrópolis: Editora Vozes, 1972. p. 26-51. (Coleção Estudos Brasileiros).

CHAUMEIL, J. P. Bones, flutes, and the dead: memory and funerary treatments in Amazonia. In: FAUSTO, C.; HECKENBERGER, $M$. (Ed.). Time and memory in indigenous Amazonia: anthropological perspectives. Florida: University Press of Florida, 2007. p. 243-283.

CISNEIROS, D. Práticas funerárias na pré-história do Nordeste do Brasil. 2004. 161 f. Dissertação (Mestrado em História) Universidade Federal de Pernambuco, Recife, 2004.

COMPERE, E. L.; BANKS, S. W.; COMPERE, C. L. Fracturas: atlas y tratamiento. México: Editorial Interamericana, 1959.

CRUZ, M. O cemitério dos Bororos. Revista do Arquivo Municipal, São Paulo, v. 98, p. 127-130, 1944.

DE PALMA, A. F. Atlas de tratamiento: fracturas y luxaciones. Barcelona: Editorial El Ateneo, 1966. Tomo I.

DUDAY, $H$. The archaeology of death: lectures in Archaeothanatology. Oxford/Oakville: Oxbow Books, 2009a. 
DUDAY, H. L'archéothanatologie ou l'archéologie de la mort (Archaeothanatology or the archaeology of death). In: GOWLAND, R.; KNÜSEL, C. (Ed.). Social archaeology of funerary remains. Oxford: Oxbow Books, 2009b. p. 30-56.

DUDAY, H.; COURTAUD, P.; CRUBEZY, E.; SELLIER, P.; TILLIER, A. M. L'Anthropologie "de terrain": reconnaissance et interprétation des gestes funéraires. Bulletins et Mémoires de la Société d'anthropologie de Paris, v. 2, n. 3, p. 29-49, 1990.

FEREMBACH, D.; SCHWIDETZKY, I.; STLOUKAL, M. Recommandations pour determiner l'age et le sexe sur le squelette. Bulletins et Mémoires de la Société d'Anthropologie de Paris, v. 6, n. 1, p. 7-45, mars 1979

GASPAR, M. D. Espaço, ritos funerários e identidade pré-histórica. Revista de Arqueologia, São Paulo, v. 8, n. 2, p. 221-237, 1994-1995.

GASPAR, M. D; DE BLASIS, P.; FISH, S. K.; FISH, P. R. Sambaqui (Shell Mound) societies of coastal Brazil. In: SILVERMAN, H.; ISBELL, W. H. (Ed.). Handbook of South American Archaeology. New York: Springer, 2008. p. 319-335.

GENOVÉS, S. Proportionality of the long bones and their relation to stature among Mesoamericans. American Journal of Physical Anthropology, v. 26, n. 1, p. 67-77, Jan. 1967.

GILL, G. W. Craniofacial criteria in the skeletal attribution of race. In: REICHS, K. (Ed.). Forensic osteology: advances in the identification of human remains. Springfield: Charles C. Thomas, 1998. p. 293-318.

HAYNES, G. Frequencies of spiral and green - bone fractures on ungulate limb bones in modern surface assemblages. American Antiquity, v. 48, n. 1, p. 102-114, Jan. 1983.

HAYNES, G.; STANFORD, D. On the possible utilization of Camelops by early man in North America. Quaternary Research, Amsterdan, v. 22, n. 2, p. 216-230, Sept. 1984.

HENSEL, R.; HENSEF, Reinhold. Die Coroados der brasilianischen Provinz Rio Grande do Sul. Zeitschrift für Ethnologie, Berlin, v. 1, p. 124-135, 1869.

HERTZ, R. A contribution to the study of the collective representation of death. In: HERTZ, R. (Ed.). Death and the right hand. Glencoe: The Free Press, 1960. p. 27-86.

HILL, A. On carnivore and weathering damage to bone. Current Anthropology, Chicago, v. 17, n. 2, p. 335-336, June 1976.

HUNTINGTON, R.; METCALF, P. Celebrations of death: the anthropology of mortuary ritual. Cambridge: Cambridge University Press, 1979.

JUNQUEIRA, P. A. O grande abrigo de Santana do Riacho (abrigo com sepultamentos no Estado de Minas Gerais). 1984. 257 f. Dissertação (Mestrado em Ciência Social - Antropologia Social) Universidade de São Paulo, São Paulo, 1984. 2 v.
KNEIP, L. M.; MACHADO, L. C. Os ritos funerários das populações pré-históricas de Saquarema, RJ: sambaquis da Beirada, Moa e Pontinha. Rio de Janeiro: Museu Nacional, 1993. p. 1-76. (Documento de Trabalho 1, Série Arqueologia).

KROEBER, A. L. Disposal of the dead. American Anthropologist, USA, v. 29, n. 3, p. 308-315, July-Sept. 1927.

LARSEN, C. S. Bioarchaeology: interpreting behavior from the human skeleton. Cambridge: Cambridge University Press, 1997.

LÉVI-STRAUSS, C. Tristes trópicos. Lisboa: Edições 70, 1993.

LOTH, S. R; ISCAN, M. Y. Morphological assessment of age in the adult: the thoracic region. In: ISCAN, M. Y. (Ed.). Age markers in the human skeleton. Illinois: Charles C. Thomas Publisher, 1989. p. 105-135.

LOWIE, R. H. The Bororo. In: STEWARD, J. H. (Ed.). Handbook of South American Indians: the marginal tribes. New York: Cooper Square Publishers, 1963. p. 419-434. v. 1.

LUPO, K. D.; O'CONNELL, J. F. Cut and tooth mark distributions on large animal bones: ethnoarchaeological data from the Hazda and their implications for current ideas about early human carnivory. Journal of Archaeological Science, v. 29, n. 1, p. 85-109, Jan. 2002.

LYMAN, R. L.; FOX, G. L. A critical evaluation of bone weathering as an indication of bone assemblage formation. Journal of Archaeological Science, v. 16, n. 3, p. 293-317, May 1989.

MARTIN, G. As pinturas rupestres do Sítio Alcobaça, Buíque-PE, no contexto da tradição agreste. Clio - Série Arqueológica, Recife, v. 1, n. 18, p. 27-49, 2005.

MARTIN, G. O cemitério pré-histórico "Pedra de Alexandre" em Carnaúba dos Dantas, RN (Brasil). Clio - Série Arqueológica, Recife, v. 1, n. 11, p. 43-57, 1995-1996.

MARTIN, G. Os rituais funerários na pré-história do Nordeste. Clio - Série Arqueológica, Recife, v. 1, n. 10, p. 29-46, 1994.

MASSET, C. Age estimation on the basis on cranial sutures. In: ISCAN, M. Y. (Ed.). Age markers in the human skeleton. Illinois: Charles C. Thomas Publisher, 1989. p. 71-103.

MEINDL, R. S.; LOVEJOY, C. O. Ectocranial suture closure: a revised method for the determination of skeletal age at death based on the lateral-anterior sutures. American Journal of Physical Anthropology, USA, v. 68, n. 1, p. 57-66, Sept. 1985.

METCALF, P. Meaning and materialism: the ritual economy of death. Man, New Series, London, v. 16, n. 4, p. 563-578, Dec. 1981.

MÉTRAUX, A. Mourning rites and burial forms of the South American Indians. América Indígena, Mexico, v. 7, n. 1, p. 7-44, Jan. 1947.

MILES, D. Socio-economic aspects of secondary burial. Oceania, v. 35, n. 3, p. 161-174, Mar. 1965. 
MÜLLER, L. M.; SOUZA, S. M. Enterramentos Guarani: problematização e novos achados. In: CARBONERA, M.; SC H MITZ, P. I. (Org.). Antes do Oeste Catarinense: arqueologia dos povos indígenas. Santa Catarina: Argos - Editora da Unochapecó, 2011a. p. 167-218.

MÜLLER, L. M.; SOUZA, S. M. Cremações e sepultamentos: as estruturas anelares do planalto. In: CARBONERA, M.; SCHMITZ, P. I. (Org.). Antes do Oeste Catarinense: arqueologia dos povos indígenas. Santa Catarina: Argos - Editora da Unochapecó, $2011 \mathrm{~b}$. p. 269-305.

MYERS, T. P.; VOORHIES, M. R.; CORNER, R. G. Spiral fractures and bone pseudotools at paleontological sites. American Antiquity, USA, v. 45, n. 3, p. 483-490, July 1980.

NEVES, W. A.; HUBBE, M.; ARAÚJO, A. G. M. A Late-paleoindian secondary ritual burial from Lagoa Santa, Minas Gerais, Brazil. Current Research in the Pleistocene, v. 19, p. 83-85, 2002.

NOELLI, F. S. Sem tekhoa não há tekó: em busca de um modelo etnoarqueológico da aldeia e da subsistência Guarani e sua aplicação a uma área de domínio no delta do Jucuí - RS. 1993. 486 f. Dissertação (Mestrado em História) - Pontifícia Universidade Católica do Rio Grande do Sul, Porto Alegre, 1993.

OLIVEIRA, A. L. do N. O Sítio Arqueológico Alcobaça: sítio referência no Vale do Catimbau - Buíque-PE. CLIO - Série Arqueológica, Recife, v. 2, n. 21, p. 5-39, 2006.

OLSEN, S. L.; SHIPMAN, P. Surface modification on bone: trampling versus butchery. Journal of Archaeological Science, $v$. 15, n. 5, p. 535-553, Sept. 1988.

PARKER PEARSON, M. The archaeology of death and burial. Texas: Texas A\&M University Press, 1999.

POTTS, R.; SHIPMAN, P. Cutmarks made by stone tools on bones from Olduvai Gorge, Tanzania. Nature, v. 291, p. 577-580, June 1981.

PROUS, A. Arqueologia brasileira. Brasília: Editora da UnB, 1992.

PROUS, A. As estruturas aparentes: os sepultamentos do Grande Abrigo de Santana do Riacho. Os sepultamentos da escavação n`1. Arquivos do Museu de História Natural da UFMG, v. 13-14, p. 21-77, 1992-1993.

RAMOS, A. Introdução à antropologia brasileira: as culturas não europeias. Rio de Janeiro: CEB, 1951. (Coleção Estudos Brasileiros, v. 1).

RAPP PY-DANIEL, A. O que o contexto funerário nos diz sobre populações passadas: o sítio Hatahara. In: PEREIRA, E.; GUAPINDAIA, V. (Org.). Arqueologia amazônica. Belém: Museu Paraense Emílio Goeldi, 2010. v. 2, p. 629-653.
RAPP PY-DANIEL, A. Arqueologia da morte no sítio Hatahara durante a fase Paredão. 2009. 151 f. Dissertação (Mestrado em Arqueologia) - Universidade de São Paulo, São Paulo, 2009.

RIBEIRO, P. A. M. Cerâmica Tupiguarani no vale do Rio Pardo. Revista do CEPA, Santa Cruz do Sul, n. 6, p. 1-54, 1978.

SAUER, N. The timing of injuries and manner of death: distinguishing among antemortem, perimortem, and postmortem trauma. In: REICHS, K. (Ed.). Forensic osteology: advances in the identification of human remains. Springfield: Charles C. Thomas, 1998. p. 321-332.

SAXE, A. A. Social dimension of mortuary practices. 1970. 240 f. Tese (Doutorado em Arqueologia) - University of Michigan, Ann Arbor, 1970.

SCHROEDER, S. Secondary disposal of the dead: cross-cultural codes. World Cultures, v. 12, n. 1, p. 77-93, 2001

SELVAGGIO, M. M. Carnivore tooth marks and stone tool butchery marks on scavenged bones: archaeological implications. Journal of Human Evolution, Amsterdan, v. 27, n. 1-3, p. 215-228, July 1994.

SHIPMAN, P.; ROSE, J. Cutmarks mimics on modern fossil bovid bones. Current Anthropology, Chicago, v. 25, n. 1, p. 116-117, Feb. 1984

SHIPMAN, P.; ROSE, J. Early hominid hunting, butchering, and carcass-processing behaviors: approaches to the fossil record. Journal of Anthropological Archaeology, Amsterdam, v. 2, n. 1, p. 57-98, Mar. 1983.

SILVA, S. F. S. M. Arqueologia das práticas mortuárias em sítios pré-históricos do litoral do Estado de São Paulo. 2005. 408 f. Tese (Doutorado em Arqueologia) - Universidade de São Paulo, São Paulo, 2005.

SILVA, S. F. S. M. Um outro olhar sobre a morte: arqueologia e imagem de enterramentos humanos no catálogo de duas coleções - Tenório e Mar Virado, Ubatuba, São Paulo. 2001. 889 f. Dissertação (Mestrado em Arqueologia) - Universidade de São Paulo, São Paulo, 2001.

SOLARI, A.; SILVA, S. F. S. M.; DI MELLO, S. Estudo de caso sobre indicadores bioarqueológicos de práticas mortuárias complexas em esqueleto humano coletado no abrigo Pedra do Cachorro, Buíque, PE. Clio - Série Arqueológica, Recife, v. 30, n. 1, p. 93-120, 2015.

SOLARI, A.; ISNARDIS, A.; LINKE, V. Entre cascas e couros: os sepultamentos secundários da Lapa do Caboclo (Diamantina, Minas Gerais). Habitus, Goiânia, v. 10, n. 1, p. 115-134, jul.-dez. 2012.

SPRAGUE, R. A. Burial terminology: a guide for researchers. New York: AltaMira Press, 2005. 
SPRAGUE, R. A. A suggested terminology and classification for burial description. American Antiquity, USA, v. 33, n. 4, p. 479485, Oct. 1968.

STRAUSS, A. Os padrões de sepultamento do sítio arqueológico Lapa do Santo (Holoceno Inicial, Brasil). Boletim do Museu Paraense Emílio Goeldi. Ciências Humanas, Belém, v. 11, n. 1, p. 243-276, jan.-abr. 2016.

STRAUSS, A. As práticas mortuárias dos primeiros sul-americanos. Arquivos do Museu de História Natural da UFMG, v. 23, p. 89-134, 2014

STRAUSS, A. As práticas mortuárias dos caçadores-coletores pré-históricos da região de Lagoa Santa (MG): um estudo de caso do sítio arqueológico "Lapa do Santo". 2010. 703 f. Dissertação (Mestrado em Genética e Biologia Evolutiva) - Universidade de São Paulo, São Paulo, 2010.

TAINTER, J. A. Mortuary practices and the study of prehistoric social systems. Advances in Archaeological Method and Theory USA, v. 1, p. 105-141, 1978.

TURNER II, C. G.; TURNER, J. A. Perimortem damage to human skeletal remains from Wupatki National Monument, Northern Arizona. Kiva, v. 55, n. 3, p. 187-212, 1990.

UBELAKER, D. H. Human skeletal remains: excavation, analysis, interpretation. Washington: Taraxacum, 1989. (Manuals on Archeology, 2)

UBELAKER, D. H.; ADAMS, B. J. Differentiation of perimortem and postmortem trauma using taphonomic indicators. Journal of Forensic Science, USA, v. 40, n. 3, p. 509-512, May 1995.

UCHÔA, D. P. A Ilha do Mar Virado: estudo de um sítio arqueológico no litoral Norte do Estado de São Paulo. CLIO - Série Arqueológica, Recife, v. 24, n. 1, p. 7-40, 2009.

UCHÔA, D. P. Arqueologia de Piaçaguera e Tenório: análise de dois sítios pré-cerâmicos do litoral paulista. 1973. Tese (Doutorado em Arqueologia) - Universidade de São Paulo, São Paulo, 1973.
UCKO, P. J. Ethnography and archaeological interpretation of funerary remains. World Archaeology, UK, v. 1, n. 2, p. 262-280, Oct. 1969

VERGNE, C. Complexidade social e ritualidade funerária em Xingó: apontamentos teóricos para compreensão das práticas mortuárias do sítio Justino, Canindé do São Francisco - SE. Canindé, Xingó, n. 9, p. 25-57, 2007

VERGNE, C. Cemitérios do Justino: estudo sobre a ritualidade funerária em Xingó, Sergipe. Sergipe: Museu de Arqueologia de Xingó/Universidade Federal de Sergipe, 2005.

VERGNE, C. Estruturas funerárias do sítio Justino: distribuição no espaço e no tempo. Canindé, Xingó, n. 2, p. 251-273, 2002.

VILLA, P.; MAHIEU, E. Breakage patterns of human long bones. Journal of Human Evolution, Amsterdan, v. 21, n. 1, p. 27-48, July 1991

WALKER, P. L. A bioarchaeological perspective on the history of violence. Annual Review of Anthropology, v. 30, p. 573-596, Oct. 2001

WALKER, P. L.; LONG, J. C. An experimental study of the morphological characteristics of tool marks. American Antiquity, USA, v. 42, n. 4, p. 605-616, Oct. 1977.

WHITE, T. D. Prehistoric cannibalism at Mancos 5MTUMR-2346 Princeton: Princeton University Press, 1992.

WHITE, T.; FOLKENS, P. A. The human bone manual. London/ San Diego: Elsevier Academic Press, 2005.

WIEBERG, D. A.; WESCOTT, D. J. Estimating the timing of long bone fractures: correlation between the postmortem interval, bone moisture content, and blunt force trauma fracture characteristics. Journal of Forensic Science, USA, v. 53, n. 5, p. 1028-1034, Sept. 2008.

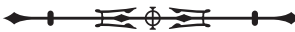


